\title{
A spectral survey of the Crisium basin region of the Moon
}

\author{
P. D. Spudis \\ Lunar \& Planetary Institute, Houston, Texas
}

D. T. Blewett, B. R. Hawke, and P. G. Lucey

Planetary Geosciences, Hawaii Institute of Geophysics \& Planetology, SOEST, University of Hawaii, Honolulu

\begin{abstract}
The Crisium basin region harbors a number of interesting features, including geochemical and radar anomalies, light plains units and possible hidden mare deposits (cryptomaria). This report presents preliminary results of a telescopic near-infrared spectral study concerning a variety of surface units in the Crisium region. Observations were made of Mare Crisium, light plains deposits north of Taruntius crater, and the terra associated with the Crisium basin.
\end{abstract}

\section{Introduction}

The Crisium basin is a multiring impact structure on the eastern portion of the Moon's nearside (Figure 1). Stratigraphic relations [e.g., Wilhelms, 1987; Spudis et al. 1989] indicate that the basin is of Nectarian age.

Extensive previous work on the stratigraphy, geologic history and remote sensing characteristics of Mare Crisium has been published [e.g., Head et al., 1978; Pieters et al., 1979]. However, many unanswered questions exist concerning the nature and origin of the highland units associated with the Crisium basin. This paper presents preliminary results concerning: 1) the composition of highland units in the vicinity of the Crisium basin, 2) the stratigraphy of the Crisium preimpact target site, 3) the nature and origin of light plains deposits, 4) the origin of geochemical anomalies in the region, and 5) the distribution of possible cryptomaria.

\section{Methods}

Near-infrared (near-IR) reflectance spectra $(0.6-2.5 \mu \mathrm{m})$ were collected with the Planetary Geosciences InSb spectrometer mounted on the Univ. of Hawaii $0.61-\mathrm{m}$ and $2.24-\mathrm{m}$ telescopes at Mauna Kea Observatory. Spectrometer apertures used in the observations described here correspond to spot sizes of $-3-27$ $\mathrm{km}$. Data collection and reduction techniques were standard [McCord et al., 1981]. The locations for which spectra were obtained appear in Figure 1, spectra are shown in Figure 2. In order to derive mineralogical information, an analysis focusing on the ferrous iron absorption band near $1 \mu \mathrm{m}$ was conducted for each spectrum, as described by Lucey et al. [1986]. Table 1 lists derived spectral parameters. The uncertainty in the spectral parameters is partly determined by the quality of the spectrum being analyzed. For the spectra with the poorest precision discussed here, we estimate the maximum uncertainties to be $\pm 0.05 \mu \mathrm{m}^{.1}$ in slope, $\pm 0.01 \mu \mathrm{m}$ in position of minimum, and $\pm 1 \%$ in depth. Parameters for higher quality spectra will have correspondingly smaller errors.

In addition, spectral mixing relationships were studied by the application of principal components analysis (PCA) (Blewett et al., 1995, and references therein]. For reference, a laboratory spectrum of an Apollo 16 soil (representing the standard telescopic site at Apollo 16) and spectra of areas in

Copyright 1995 by the American Geophysical Union.

Paper number $95 \mathrm{GL} 03079$

0094-8534/95/95GL-03079\$03.00
Mare Crisium (from Pieters et al. [1979]) were also included in the PCA. The analysis found that the first two principal components (PCs) are responsible for $-97 \%$ of the variation in the spectra. Calculating the PC scores for a spectrum allows it to be plotted as a point in PC-space (Figure 3 ). The use of this plot to examine spectral mixing is discussed below. Linear mixing was assumed [Singer and McCord, 1979].

\section{Results and Discussion \\ Crisium Highlands}

Proclus crater. Proclus $\left(16.1^{\circ} \mathrm{N}, 46.8^{\circ} \mathrm{E} ; 28 \mathrm{~km}\right.$ diameter) is a Copernican age impact crater located in the highlands $W$ of Mare Crisium (Figure 1 ). This position is near a prominent Crisium basin ring, therefore Proclus should primarily expose material emplaced by the Crisium impact [Spudis et al., 1989]. A spectrum of Proclus (no. 2 in Figure 2) was collected with a large aperture, such that flux was contributed by almost the entire interior of the crater. This spectrum was determined to have a band minimum located at $0.93 \mu \mathrm{m}$ and a band depth of $\sim 4 \%$, consistent with noritic anorthosite. A spectrum of the $E$ rim of Proclus was presented by Pieters [1986] (shown here in Figure 2, no. 3), who interpreted it as indicative of noritic anorthosite. However, Pieters [1986] noted that some spectral parameters fell outside the range typical of other noritic anorthosite spectra. This could be due in part to the freshness of the area for which the spectrum was collected.

Circum-Crisium massifs. Spectra were oblained for four highland massifs located $N, S$ and $S W$ of Mare Crisium (Figures 1 and 2). Two of these massifs are on the mare-bounding ring. These observations should characterize the spectral properties of surface materials emplaced by the Crisium impact. The nearby Serenitatis basin is thought to be younger than Crisium, so some contribution of material from the Serenitatis impact cannot be ruled out [Spudis, 1993]. The spectra (Figure 2, nos. 4-7) have band minima located at 0.92 to $0.94 \mu \mathrm{m}$, and band depths of $2-4 \%$. The spectral characteristics indicate the presence of highland rocks with mafic assemblages dominated by $\mathrm{Ca}$-poor pyroxene. A noritic anorthosite composition is indicated, though slightly steeper continuum slopes in several spectra with deeper bands may attest to the presence of anorthositic norite. No pure anorthosites [e.g., Hawke at al., 1993] were identified, but it should be noted that only a few areas on the inner basin rings were observed.

Taruntius peak. Located at $5.6^{\circ} \mathrm{N}, 46.5^{\circ} \mathrm{E}$, the $56 \mathrm{~km}$ diameter crater Taruntius lies SW of Crisium. The central peak of Taruntius probably exposes material from beneath deposits emplaced by the Crisium impact [Spudis et al., 1989; Spudis, 1993]. A spectrum for the peak (Figure 2, no. 8) exhibits spectral parameters consistent with a noritic anorthosite or anorthositic norite. The band depth $(\sim 6 \%)$ is greater than that of the circum-Crisium highlands spectra described above, and the continuum slope is steeper. This suggests that the material exposed in the peak is slightly more mafic (anorthositic norite) than that composing the majority of the circumCrisium highlands. Thus, the composition of the highlands in the vicinity of Taruntius may become more mafic with depth.

Eimmart A. This very fresh $7 \mathrm{~km}$ crater $\left(24.0^{\circ} \mathrm{N}, 65.7^{\circ} \mathrm{E}\right)$ is located near the rim of a highland crater NE of Crisium, at the 


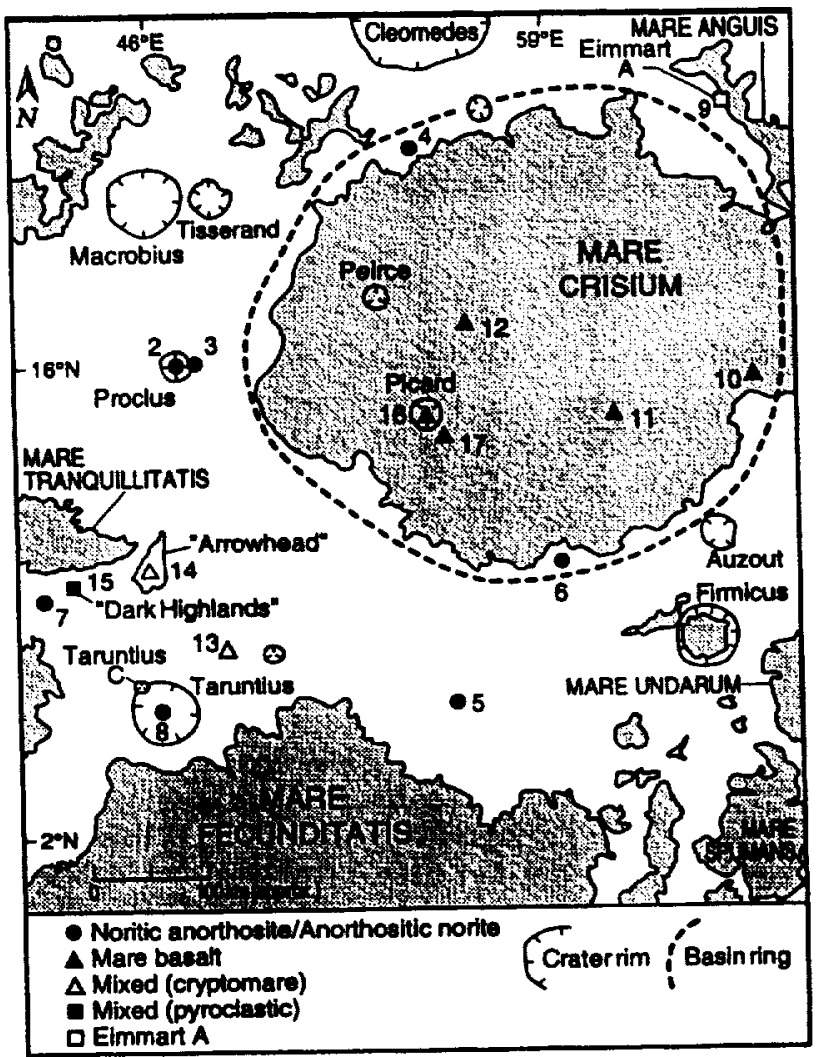

Figure 1. Sketch map of the Crisium region. Numbers identify near-IR spectra listed in Table 1 and shown in Figure 2. Symbols indicate the location and lithology of areas for which spectra have been collected and interpreted.

edge of Mare Anguis (Figure 1). In previous spectral analysis Pieters [1986, 1993] noted the extremely strong (21\%) I $\mu \mathrm{m}$ absorption band of the Eimmart $A$ spectrum (shown in Figure 2 , no. 9), and favored an olivine/low-Ca pyroxene mixture to account for the position of the $1 \mathrm{\mu m}$ band minimum, its broad shape, and shape of the $2 \mu \mathrm{m}$ band. On this basis, Eimmart A was proposed as the possible source crater for meteorite ALHA81005, a highland breccia [Pieters et al., 1983].
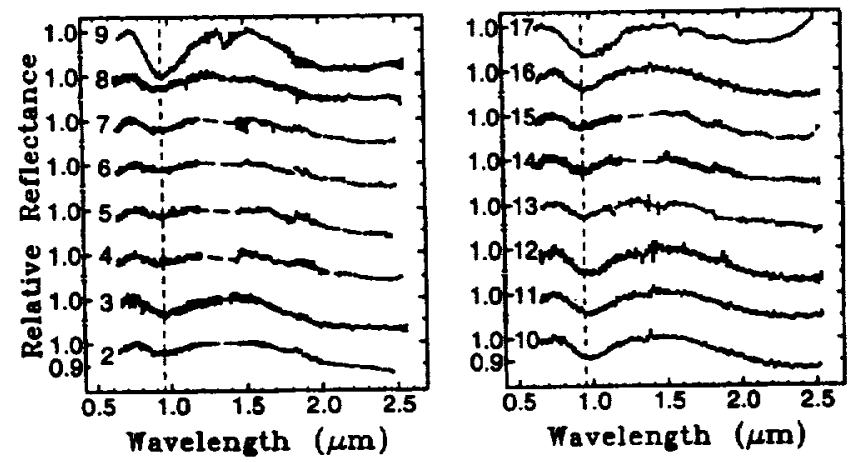

Figure 2. Continuum-removed spectra (identified by the numbers listed in Table 1) for features discussed in the text. Some spectra show incomplete removal of atmospheric water absorptions due to variable observing conditions. Gaps from 1.2 to $1.4 \mu \mathrm{m}$ occur in some spectra because of an instrumental problem during the observations. Vertical dashed lines at 0.95 $\mathrm{\mu m}$ are an aid to noting spectral variations.
Table 1. Spectral Information

\begin{tabular}{llcccc}
\hline \multicolumn{1}{c}{ Spectrum } & A & B & C & D \\
\hline 1 & Apollo 16 & 0.59 & 0.90 & 2.7 & - \\
2 & Proclus & 0.58 & 0.93 & 4.4 & s \\
3 & Proclus East Rim & 0.45 & 0.95 & 6.3 & s \\
4 & Massif N of Crisium & 0.59 & 0.92 & 3.2 & s \\
5 & Highlands S of Crisium 1 & 0.60 & 0.92 & 3.0 & $\mathrm{~m}$ \\
6 & Massif S of Crisium & 0.62 & 0.94 & 2.3 & $\mathrm{~s}$ \\
7 & Bright HL SW of Crisium & 0.62 & 0.93 & 4.2 & $\mathrm{~s}$ \\
8 & Taruntius Peak & 0.64 & 0.92 & 5.6 & $\mathrm{~s}$ \\
9 & Eimmart A & 0.32 & 0.96 & 20.1 & $\mathrm{~s}$ \\
10 & Mare Crisium C & 0.74 & 0.98 & 8.6 & $\mathrm{f}$ \\
11 & Mare Crisium D & 0.71 & 0.99 & 8.2 & $\mathrm{f}$ \\
12 & Mare Crisium 40 & 0.68 & 0.99 & 10.0 & $\mathrm{f}$ \\
13 & Taruntius Plains 1 & 0.69 & 0.95 & 5.8 & $\mathrm{f}$ \\
14 & Arrowhead Plains & 0.71 & 0.93 & 5.3 & $\mathrm{f}$ \\
15 & Dark HL SW of Crisium & 0.68 & 0.92 & 5.5 & $\mathrm{~m}$ \\
16 & Picard Center & 0.64 & 0.97 & 7.9 & $\mathrm{~m}$ \\
17 & Mare SE of Picard & 0.76 & 0.99 & 12.9 & $\mathrm{f}$ \\
\hline
\end{tabular}

A: continuum slope, $1 / \mu \mathrm{m} ; \mathrm{B}$ : location of band minimum, $\mu \mathrm{m}$; C: band depth, $\%$; $D$ : surface slope, $s=$ steep, $f=$ flat, $m=$ mixed.

However, photography by Lunar Orbiter IV shows Eimmart A to be located largely in the surrounding mare deposit, and thus mare basalt was likely excavated by Eimmart A. Both mare and highland material should be present in the area for which the spectrum was obtained. The presence of mare material could partly account for the spectral characteristics of the crater.

\section{Light Plains and Cryptomaria}

Terrain $N$ and NE of Taruntius. This smooth, lowlying area of moderate albedo has been mapped as Imbrian age light plains (unit Ip) and smooth terra (Its) by Wilhelms [1972]. The terrain is distinctive in several remote sensing data sets. The color-difference image produced by Whitaker (see Fig. 5.20 of Wilhelins [1987]) shows the area to be slightly "bluer" than the nearby highlands. In addition, 3.8$\mathrm{cm}, 70-\mathrm{cm}$ and $7.5-\mathrm{m}$ radar images [Zisk el al., 1974; Thompson, 1974, 1978] show that this region is characterized by radar returns more similar to mare than highland surfaces. Bielefield et al. [1978] examined correlations between albedo data and $\mathrm{Al} / \mathrm{Si}$ and $\mathrm{Mg} / \mathrm{Al}$ ratios derived from Apollo orbital geochemical measurements. Their classification placed the area $\mathrm{N}$ and NE of Taruntius in a unit that also includes mare surfaces in the region. Studies of orbital geochemical data [Hawke et al., 1985] indicate that the composition of this area can be represented as a combination of $46 \%$ highland material and $54 \%$ mare basalt.

A near-IR spectrum for a location on the light plains $\mathrm{N}$ of Taruntius was collected (Figure 2, no. 13). The spectrum has a band minimum slightly longward of $0.95 \mu \mathrm{m}$ and a depth of $-6 \%$, indicating a significant mare basalt component. In order to determine the amount of mare material present in the area for which the spectrum was obtained, a mixing model based on the results of PCA was utilized. The model employs the PC-space plot of Figure 3. In this plot, spectral endmembers are found at the extremes, while mixtures lie within the boundaries defined by the endmembers. In Figure 3 , several clusterings of plausible endmembers are found. Spectra for Proclus (nos. 2 and 3 ) represent fresh highland material. The mature highland spectra Apollo 16 (1), Massif $N$ of Crisium (4), and Highlands $S$ of Crisium 1 (5) plot close together. Mature mare spectra fall into two groups: Mare Crisium "C," "D," and "40" $(10,11,12)$ and the spectrum for mature mare near Picard (17). Spectra for areas believed to contain combinations of mare and highland material lie along a mixing line between mature highlands and the "C-D-40" mature mare. Thus, it is reasonable to choose Apollo 16 and Mare Crisium $C$ as the endmembers in modeling these mixture spectra. The relative contribution of an 


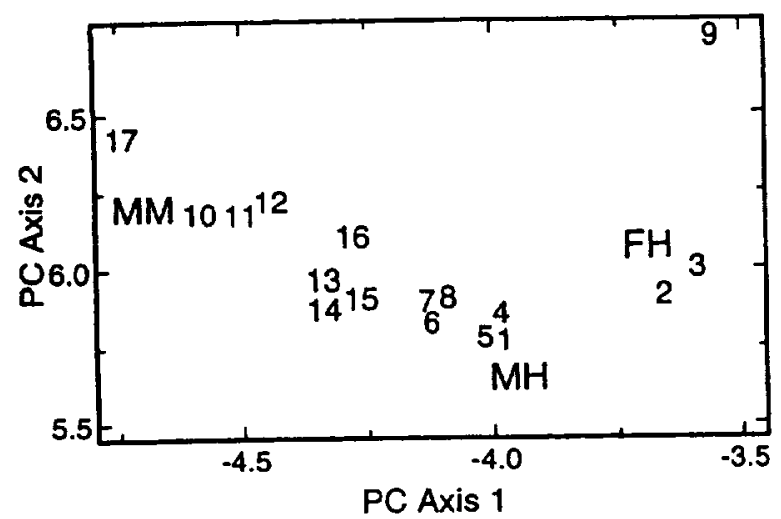

Figure 3. Plot showing spectra (identified by the numbers listed in Table 1) projected into the space defined by the first two principal components of variation. Axis 1 is related to the near-IR spectral slope (spectra with steeper slopes have morenegative scores on Axis 1). Axis 2 is related to the characteristics of the $1 \mu \mathrm{m}$ absorption band (spectra with deeper bands have higher scores on Axis 2). Groupings of plausible end-members are indicated by $\mathrm{MM}$ (mature mare), $\mathrm{MH}$ (mature highlands), and FH (fresh highlands).

endmember to a mixture spectrum is equal to 1-(distance of the mixture from the endmember/total distance between endmembers). Results indicate that the "Taruntius Plains 1" spectrum can be modeled as a $44 \%$ contribution of flux from the highland endmember, and $56 \%$ from the mare endmember.

The spectral results together with the other remote sensing information cited above favor the following interpretation for the origin of the units $\mathrm{N}$ and NE of Taruntius. Mare basalt was emplaced in this area prior to the formation of Taruntius crater. The present morphology of the deposits is consistent with an extrusive volcanic origin. The material exhibits embayment relationships with the adjacent more rugged highland terrain, and a possible mare-type ridge is present [Hawke et al., 1985]. The mare surface was then contaminated by variable amounts of highland material as a result of Taruntius and other impacts.

The area $\mathrm{N}$ and NE of Taruntius thus qualifies as a cryptomare as defined by Head and Wilson [1992]. Other examples of plains units that were produced by the burial or contamination of a pre-existing mare surface by highland debris have been previously described [Hawke and Bell, 1981; Bell and Hawke, 1984; Head et al., 1993; Blewett et al., 1995; Antonenko et al., 1995], indicating that this may be a common origin for light plains and smooth terra units on the lunar surface.

"Arrowhead" shaped plains. A triangular patch of plains material is found in the circum-Crisium highlands due $\mathrm{N}$ of Taruntius at $-10^{\circ} \mathrm{N}, 46.3^{\circ} \mathrm{E}$ (Figure 1 ). Several factors distinguish this area. It has a lower albedo than the surrounding highlands and contrasts with them in the Whitaker color-difference photograph. Additionally, this area possesses a high $\mathrm{Mg} / \mathrm{Al}$ ratio, similar to that of mare soils, as determined from orbital X-ray measurements [Schonfeld, 1981]. The area corresponds to exposures of Imbrian age units Ip and Its on the geologic map of the region [Wilhelms, 1972]. A spectrum of the arrowhead plains (Figure 2, no. 14) has a stronger absorption band $(-5 \%)$ than the measured Crisium highland massifs, suggesting a greater abundance of pyroxene in the plains surface. From the location of the arrowhead plains spectrum in the PC. space plot of Figure 3 and the spectral mixing model described above, we determine that a roughly $50-50$ mixture of the mare and highland endmember spectra produces a reasonable match to the spectrum of the arrowhead plains. Hence this area probably represents an Imbrian-age mare deposit that has been contaminated by significant amounts of highland debris.
Dark highlands SW of Crisium. The highlands along the eastern shore of Mare Tranquillitatis contain a distinctive strip of low-albedo plains, at $-9.5^{\circ} \mathrm{N}, 43.5^{\circ} \mathrm{E}$. This "smooth terra material (Its)" unit has been described as having an uncertain origin, possibly thin mare flows mantling the terra [Wilhelms, 1972]. Such a mantling origin was invoked to explain the low albedo of some highland units SW of Taruntius [Wilhelms, 1980] where mare basalt flows moved from a higher level to a lower one over the intervening highland terrain. The spectrum obtained for the dark highlands SW of Crisium is shown in Figure 2 (no. 15). It has spectral parameters similar to those of the "arrowhead" plains described above, and falls very close to it in PC-space (Figure 3). The relatively strong absorption band indicates a mare basalt component, and mixing analysis determined that approximately equal amounts of flux were contributed to the dark highlands spectrum by mare and highland spectral types.

In order to investigate the origin of possible volcanic deposits in the dark highlands, an analysis was conducted using Lunar Topographic Orthophotomap LTO61B4. Consideration of the elevations of the mare and highland surfaces in the area shows that, unlike the situation SW of Taruntius, mare flows did not move down slope across highland terrain. In addition, it is unlikely that lava was erupted from a large number of vents in separate areas of the dark highlands, since no obvious vents are apparent in Apollo and Lunar Orbiter photography. In portions of the area, dark material appears to mantle and subdue rugged subjacent terrain. Similar characteristics are displayed by the thinner portions of lunar dark mantle deposits of pyroclastic origin [Gaddis ef al., 1985]. Thus, in the dark highlands SW of Crisium, explosive volcanism may have emplaced pyroclastic debris with spectral properties similar to some mare deposits. Localized pyroclastic deposits dominated by mare basalt were previously identified at other locations by Hawke et al. [1989].

\section{Mare Basalt Deposits}

Crisium mare units. Three spectra of mare units from Pieters et al. [1979] were used in the PCA described above. The results of our analysis of these spectra are given in Table 1. The spectral parameters are typical of mature basaltic regoliths. Further discussion of other remote sensing characteristics, compositional interpretations, and geologic history of the Mare Crisium basalts is given by Head et al. [1978] and Pieters et al. [1979].

Picard. The crater Picard $\left(14.6^{\circ} \mathrm{N}, 54.7^{\circ} \mathrm{E}\right)$ is located in western Mare Crisium. It has been proposed that the floor of Picard contains mature non-mare soil [Head et al., 1978]. If this is the case, then it could be inferred that the Picard impact penetrated the mare deposits and exposed subjacent highland material. A spectrum for the center of the crater (Figure 2, no. 16) has a band minimum at $0.97 \mu \mathrm{m}$ and a depth measuring $-8 \%$. A spectrum for an area of mature mare soil to the SE of Picard (17) has a band minimum at $0.99 \mu \mathrm{m}$ and has a strength of $-13 \%$. The spectral parameters are consistent with the presence of a highland component in the floor material. Figure 3 shows that the Picard center spectrum falls approximately on a line between the highland endmember spectra $(1,4,5)$ and the "Mature Mare SE of Picard" spectrum (17), with a small displacement toward fresher material.

The isopach map of Crisium basalt thicknesses presented by DeHon and Waskom [1976] indicates that the mare unit in the vicinity of the Picard target site is $<1.5 \mathrm{~km}$ thick. Hence, if Picard ( $23 \mathrm{~km}$ diameter) excavated to a maximum depth of 0.10 times its diameter, the mare basait could have been penetrated and subjacent highland material exposed. 


\section{Summary and Implications}

1. The several measured highland massifs associated with the Crisium basin are dominated by noritic anorthosite, though some areas may be composed of anorthositic norite. The walls and rim of Proclus crater, which likely excavated material emplaced by the Crisium basin-forming event, are of noritic anorthosite composition. Apparently the crust in the Crisium preimpact target site was dominated by noritic anorthosite and anorthositic norite.

2. The Taruntius central peak exposes slightly more mafic, pre-Crisium, highland material. Thus, the composition of the lunar crust in this area may become more mafic with depth.

3. Cryptomaria have been identified in the highlands SW of the Crisium basin, and they are associated with geochemical and radar anomalies. These anomalies are caused by the presence of variable amounts of mare material in the regoliths developed on the surfaces of the cryptomaria.

4. Some light plains deposits in the Crisium region appear to be ancient mare basalt deposits contaminated with variable amounts of highland material. Early mare volcanism was more common in the Crisium region than previously thought.

5. Explosive volcanism emplaced mafic pyroclastic debris in portions of the highlands SW of Crisium.

6. Spectral studies indicate that the floor of Picard crater is composed of a mare/highland mixture, implying that the Picard impact penetrated the basalts of Mare Crisium and exposed underlying highland material.

Acknowledgments. This work was made possible by NASA grant NAGW-237. D.T.B. was supported by a Hawaii Space Grant College graduate fellowship. Comments by J.L. Whitford-Stark, M.J. Gaffey, and an anonymous reviewer led to major improvements in this paper. HIGP contribution number 821 , SOEST contribution number 3919.

\section{References}

Antonenko, 1., 3. Head, J. Mustard, and B. Hawke, Criteria for the detection of lunar cryptomaria, Earth, Moson, Planets, in press, 1995.

Bell, J. F. and B. R. Hawke, Lunar dark-haloed impact craters: Origin and implications for early mare volcanism. J. Geophys. Res., 89. 6899-6910, 1984

Bielefeld, M., R. Wildey, and J. Trombka, Correlation of chemistry with normal albedo in the Crisium region, in Mare Crisium (R. Merrill and J. Papike, Eds.), Pergamon, New York, 33-42, 1978.

Blewett, D. T., B. R. Hawke, P. G. Lucey, G. J. Taylor, R. Jaumann, and P. Spudis, Remote sensing and geologic studies of the SchillerSchickard region of the Moon, J. Geophys. Res., in press, 1995.

DeHon, R. A. and J. D. Waskom, Geologic structure of the eastern mare basins, Proc. Lunar Sci. Conf., 7th, 2729-2746, 1976.

Gaddis, L. R., C. M. Pieters, and B. R. Hawke, Remote sensing of lunar pyroclastic mantling deposits, Icarus, 61, 461-489, 1985.

Hawke, B. R. and J. F. Bell, Remote sensing studies of lunar dark-halo impact craters: Preliminary results and implications for early volcanism, Proc. Lunar Planet. Sci. Conf., /2th. 665-678, 1981.

Hawke, B. R., P. D. Spudis, and P. E. Clark, The origin of selected lunar geochemical anomalies: Implications for early volcanism and the formation of light plains, Earth, Moon, Planets, 32, 257-273, 1985.
Hawke, B. R., C. R. Coombs, L. R. Gaddis, P. G. Lucey, P. D. Owensby, Remole sensing and geologic studies of localized dark mantle deposits on the Moon, Proc. Lunur Planet. Sci. Comf., 19th, 255-268. 1989.

Hawke, B. R., et al., Remote sensing studies of the terrain northwest of Humorum basin, Geophys. Res. Lett., 20, 419-422. 1993.

Head, J., J. Adams, T. McCord, C. Pieters, and S. Zisk, Regional stratigraphy and geologic history of Mare Crisium, in Mare Crisium (R. Merrill and J. Papike. Eds.). Pergamon, New York, 43-74, 1978.

Head, J. W., and L. Wilson, Lunar mare volcanism: Stratigraphy, eruption conditions, and the evolution of secondary crusts, Gerschim. Cosmochim. Acta, 56, 2155-2175, 1992.

Head, J. W., et al., Lunar impact basins: New data for the western limb and far side (Orientale and South Pole-Aitken Basins) from the first Galileo flyby, J. Geophys. Res., 98, 17,149-17,181, 1993.

Lucey, P. G., B. R. Hawke. C. M. Pieters, J. W. Head, and T. B. McCord, A compositional study of the Aristarchus region of the Moon using near-infrared reflectance spectroscopy. Proc. Lunar Planet. Sci. Conf. 16th, D344-D354, 1986.

McCord, T. B., et al., Moon: Near-infrared spectral reflectance, a first good look, J. Geophys. Res., 86, 10,883-10,892, 1981.

Pieters, C. M., Composition of the lunar highlands crust from nearinfrared reflectance spectroscopy. Rev. Geophys., 24, 557-578, 1986.

Pieters, C. M., Compositional diversity and stratigraphy of the lunar crust derived from reflectance spectroscopy, in Remole Geochemical Analysis, (C. Pieters and P. Engler, Eds.), Cambridge Univ. Press. Cambridge, pp. 309-339. 1993.

Pieters, C., T. B. McCord, J. W. Head, J. B. Adams, and S. H. Zisk, Mare Crisium geologic units: Implications of additional remote sensing data. Proc. Lunar Planet. Sci. Conf., 1Oth, 2967-2973, 1979.

Pieters, C. M. B. R. Hawke, M. Gaffey, and L. A. McFadden, Possible lunar source areas of meteorite ALHA81005: Geochemical remote sensing information, Geophys. Res. Lett. 10, 813-816, 1983.

Schonfeld, E., High spatial resolution Mg/Al maps of the western Crisium and Sulpicius Gallus regions, Proc. Lunar Planet. Sci. Conf., 12th, 809-816, 1981 .

Singer, R. B. and T. B. McCord, Mars: Large scale mixing of bright and dark surface materials and implications for analysis of spectral reflectance, Proc. Lunar Planet. Sci. Conf., JOth, 1835-1848, 1979.

Spudis, P. D., B. R. Hawke, and P. G. Lucey. The lunar Crisium basin: Geology, ringe, and deposits, Lunar Planet. Sci. XX, 1042-1043, 1989.

Spudis, P. D., The Geology of Multi-Ring Impact Basins, Cambridge Univ. Press, Cambridge, 263 pp., 1993.

Thompson, T. W., Atlas of lunar radar maps at $70-\mathrm{cm}$ wavelength, Moon, 10. 51-85, 1974.

Thompson, T. W., High resolution lunar radar map at 7.5 meter wavelength, Jcurus, 36, 174-188, 1978.

Wilhelms, D. Geologic map of the Taruntius quadrangle of the Moon, U.S. Geol. Surv. Map, 1-722. 1972.

Wilhelms, D. Stratigraphy of Pan of the Lunar Nearside, U.S. Geol. Surv. Prof. Pap. 1046-A, A35-A39, 1980.

Wilhelms, D., The Geologic History of the Moon, U.S. Geol. Surv. Prof. Pap. 1348, 1987.

Zisk, S., G. Pettengill, and G. Catuna, High-resolution radar maps of the lunar surface at $3.8-\mathrm{cm}$ wavelength, Moon, 10, 17-50, 1974.

D. T. Blewett. B. R. Hawke, P. G. Lucey, PGD, 2525 Corren Rd., Honolulu, HI 96822. (e-mail dave kahana.pgd.hawaii.edu).

P. D. Spudis, Lunar \& Planetary Institute 3600 Bay Area Blvd., Houston, TX 77058.

(Received Dec. 27, 1994; Revised July 3, 1995; Accepted July 20, 1995.) 